\title{
Assessment Capability Forest Regeneration in Different Geographical Aspects Approach Landscape Ecology
}

\author{
Arash Karami ${ }^{1}$, Saeed Karimi ${ }^{2 *}$, Elham Shahi ${ }^{2}$ \\ ${ }^{1}$ Expert at the Department of Forests, Rangeland and Watershed, Tehran, Iran \\ ${ }^{2}$ Faculty of Environment, University of Tehran, Tehran, Iran \\ Email: *karimis@ut.ac.ir
}

How to cite this paper: Karami, A., Karimi, S. and Shahi, E. (2017) Assessment Capability Forest Regeneration in Different Geographical Aspects Approach Landscape Ecology. Open Journal of Ecology, 7, 535-553.

https://doi.org/10.4236/oje.2017.79036

Received: June 28, 2017

Accepted: August 6, 2017

Published: August 9, 2017

Copyright $\odot 2017$ by authors and Scientific Research Publishing Inc. This work is licensed under the Creative Commons Attribution International License (CC BY 4.0).

http://creativecommons.org/licenses/by/4.0/

\section{(c) (i) Open Access}

\begin{abstract}
In order to determine the relationship between physiographical factors and regeneration changes in forests, and to improve and model natural regeneration status, Gorazbon district in Kheyrod Forest was selected for the study. All available regeneration patches in the area were selected. To achieve spatial structure and quantify metrics related to regeneration patches, the analysis of landscape metrics was used. The results show that 692 regeneration patches were identified at the level of different directions. LAND Metric show the most regeneration percent is related to the western (9\%), southern $(8.66 \%)$, flat areas $(8.33 \%)$, northern $(5.68 \%)$ and eastern $(4.73 \%)$, respectively. In total, the patch coverage level percentage was calculated in the landscape $(8.31 \%)$. The results related to patch shape metric show that most shapes of patches follow polygon structures and do not have fixed shapes. Results related to the average area of the patch metric show that the average level of patches is between 4 and $5 \mathrm{R}$. The maximum and minimum distance between patches was observed in the survey between 39 and $520 \mathrm{~m}$ respectively. According to the results of the distance average between patch metric, the distribution of patches is random in the southern and western directions, flat areas and pile, but it is uniform in northern directions. It should be noted that the distribution and structure of patches in the northern directions has a better distribution and homogeneity than the other directions. Its canals are used as a natural regeneration model to follow the natural phenomena in forest sustainable management.
\end{abstract}

\section{Keywords}

Geographical Directions, Natural Distribution, Kheyrod Forest, Metrics, Landscape 


\section{Introduction}

Today, forests are considered the main components of stability in a landscape [1], yet the ecosystems influenced by various disturbances during the time will suffer changes, destructive and constructive dynamism. Therefore in recent decades, the sustainable management of forest ecosystems as dynamic ecosystems for the stability of their functions is considered one of the most important challenges for managers, researchers, specialists, and architects [1] [2].

The dynamism of forest ecosystems is variable due to different environmental factors [3]. Environmental disturbances have profound impacts on the dynamism of forest landscape [4].

Ecosystems are usually established hierarchically at the level of global, continental, national, regional, provincial, landscape, patch (mass), plant, tissue, cell and genotype. The dynamism of forest landscape is established at the level of tree or patch [5] [6].

Although basic processes exist at all levels, it is desirable to know lower level processes to know the real world and to manage forest ecosystem better [7]. Hence, ecosystems should be studied based on the activities of lower level details.

Generally, there are two types of disturbances in forest landscape: 1) Natural destructive disturbances of forest ecosystem (fire, disease, insect attack, etc.), 2) Natural constructive disturbances of forest ecosystem (natural regeneration, natural selection, competition, etc.) [8].

Some natural disturbances are constructive and they play an important ecological role in forest ecosystems [9]. Also, they can be used to help the diversity and sustainability of forest landscapes, nutrient cycling, species evolution, and above all the reconstruction and establishment of forests, etc. and they can be the best model to construct the nature for sustainable management of forests [10] [11].

Today, the sustainable management of forests and the monitor of the sustainability of forest functions are significant.

Environmental function, wood production function, etc. are among the important forest functions and regeneration which is a criterion to control the sustainability [12].

Undoubtedly, natural regeneration is one of the most important factors for the development and sustainability of forests and it is essential to survive and sustain them. In fact, it is one of the principles to achieve sustainable management of forests [13].

In forest ecosystems in mountainous regions, due to variable weather conditions and topography, natural disturbances and especially natural regeneration essential for forest survival [14] occur due to various factors such as physiographic factors (slope, direction, altitude, soil moisture and other factors), which has a direct effect on the composition, distribution, shape, size, distance, structure and interaction of regeneration patches [15]. 
As mentioned, many factors are effective in dispersing and establishing forest regeneration patches [16]. Since various geographical positions use sun energy and light unequally, ecologic position and vegetation image are different in various positions [3]. In other words, establishing restoration which is a limiting factor in forest regeneration process and a determining factor in distribution of communities is a natural phenomenon related to forest dynamics and it is interpretable by various parameters including different geographical directions on a large scale [17].

Recognizing, protecting and supporting restoration is essential to survive forest ecosystem at the level of landscape view and it requires a comprehensive study to recognize various factors affecting on it.

Kotwalp et al. (2008) stated that the landscape of forests is changing rapidly due to the permanent trend of tree mortality [8] and the formation of regeneration patches is started by the death and fall of one or more trees in Fagus orientalis Lipsky [17].

In this regard, Mirkazemi (1995) studied the present state of natural regeneration of beech in Fagus orientalis Lipsky of the pilgrimage forestry plan (Dung Generation Reproduction-Series 8) and concluded that abundant regeneration is more on the northwestern, northern, northeastern directions respectively and it is better on the edge than on other places [18].

In another study, Sefidi et al. (2011) studied the situation of eastern beech regeneration patches in Gorazbon District of northern forests of Iran and they stated that the smallest patch size is 23.7 , the average patch size is 206 and the biggest patch size is $1808 \mathrm{~m}^{2}$ and totally regeneration patches form $9.3 \%$ forest level [19].

Investigating the effect of various physiographic factors including altitude from sea level, hillside direction and slope on regenerating various species is of great importance. Also, it can be an important and effective step in the protection and restoration of important forest species [20].

Light intensity and patch size are directly related. In other words, the bigger the patch level is, the more light intensity is inside the patch. Therefore, the establishment of light species with grass species will increase and the number and type of useful seedlings for forest survival is reduced [21].

The size of patch surface is of great importance and the larger this size is, the less the possibility of its closing is.

Furthermore, the results of natural regeneration study of Quercus castaneifolia in Sordar Noor wood (Jalali, et al., 2000) indicated that this type has a better regeneration in low heights, southern and southeastern hillside and less slopes [22].

On the other hand, Yimer et al. (2006) investigated change in environmental characteristics (including slope, direction and altitude) can influence energy distribution, plant nutrition and distribution of regeneration patches [23].

Interpretation of changes in shape, size, distance and percentage of regeneration patches based on the concepts and theories of the ecology principles of 
landscape helps to change forest landscape and management methods of forests from the patch surface to the scale of the landscape and ultimately the global scale.

In order to better understand the forest ecosystem and the sustainable management of its functions, the quantification of different measures of regeneration patches to study and compare the regeneration success in different geographical directions can be an effective help in promoting the goals of sustainable forest management [21].

Awareness of metrics such as spatial distribution, patch pattern, average distance of patches, the most repeated patch pattern, total patch area relative to forest surface, patch spatial length in each geographical direction is of considerable importance and has a particular concept [20].

As it was already mentioned, various environmental factors affect the distribution, shape, size of regeneration patches.

Although a lot of studies have been done to discover these relationships, it is not possible to judge correctly about the environmental factors affecting the metrics of regeneration patches by pure statistical methods. That means the variables under study have a lot of changes and there are complex actions between environmental and plant variables and the observed correlations are often associated with uncertainty [22].

On the other hand, population and dispersion pattern based on the local occurrence of species can be mapped [24], which means it is feasible to obtain useful information for continuous monitoring forest sustainability by the spatial impression of regeneration patches and the record and analysis of each related metric in GIS and Fragstats environments.

In fact, the purpose of this study is to identify the following issues during the case study:

1) Describing the composition status and spatial distribution of regeneration patches in different geographical directions;

2) Comparing measured metrics in each direction;

3) Reducing the structure and characteristics of regeneration patches and ecological analysis of patches in the forest structure and view;

4) Evaluating the role of patches in improving ecological functions and investigating the type of corrective actions for improving forest ecological structure status and processes associated with it.

\section{Materials and Methods}

\subsection{Study Area}

To properly execute this research based on its objectives, it seems necessary that a forest with less interference should be considered. Accordingly, the study area was the Research Educational Forest of Tehran University (Kheirood Forest) located in vegetated Hirkani area in north of Iran (Figure 1).

The total area of the region is about 8000 hectares, which consists of 8 parts 


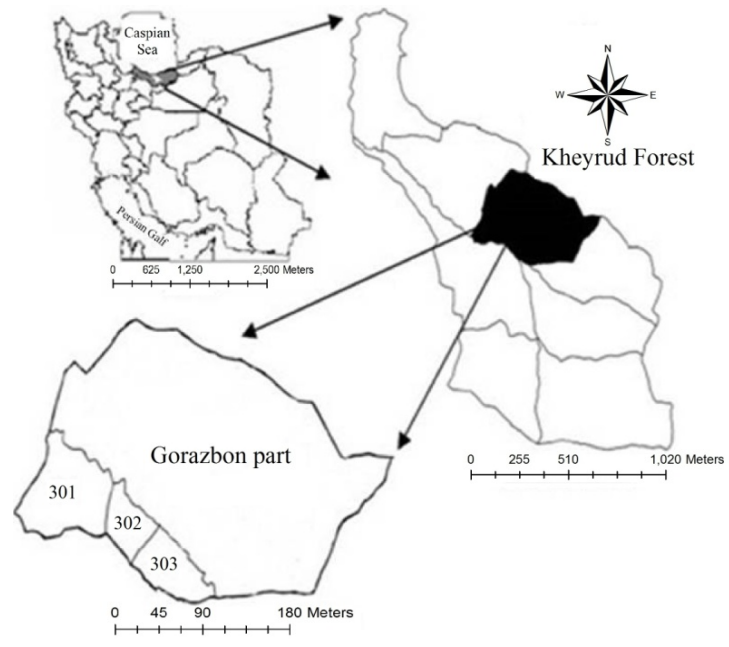

(a)

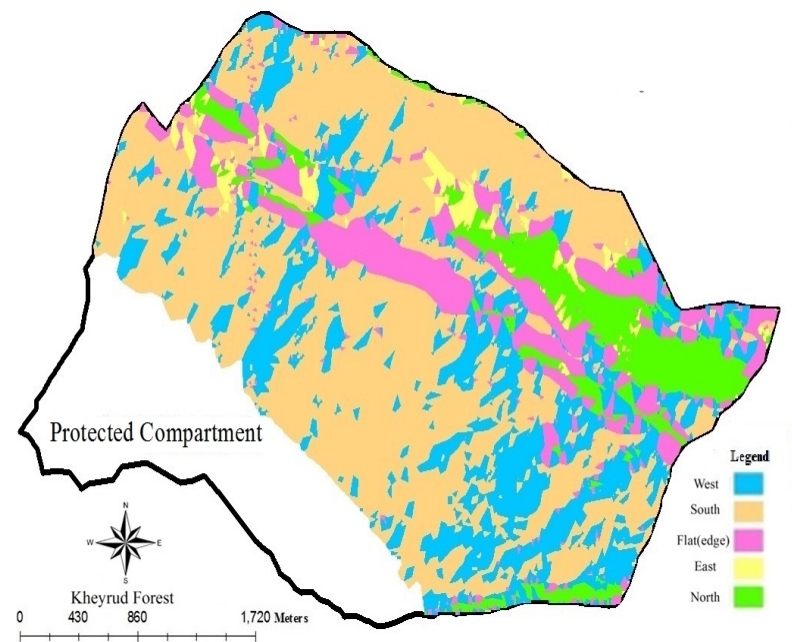

(b)

Figure 1. (a) Map of the study area and (b) Classification map of the geographical directions of Gorazbon district.

and the whole district of Gorazbon, except for supporting parcels having a high slope, comprises the context of this study.

Forestry plan is prepared for this district, but exploitation has not yet begun in accordance with the project booklet. Gorazbon district, with an area of about 1001 hectares, is located in the orbit of $30^{\prime \prime} 32^{\prime} 51^{\circ}$ to $29^{\prime \prime} 35^{\prime} 51^{\circ}$ eastern longitude and $25^{\prime \prime} 37^{\prime} 36^{\circ}$ to $30^{\prime \prime} 34^{\prime} 36^{\circ}$ northern latitude. The climate of the Mediterranean region is at an average annual temperature of $15.3^{\circ} \mathrm{C}$ and the total annual precipitation is between $1300-16,000 \mathrm{~mm}$ [25]. The geological organizations in Gorazbon district is composed of limestones and limestone marls belonging to Miocene and Palaeocene periods from the third era and the limestones belonging to the Upper Cretaceous from the second periods and with deep soils on the mother rock. The minimum altitude in this district is 800 meters and the maximum is 1400 meters above sea level. Also, the average slope of this district was calculated based on the slope map analysis of $40 \%$ [21].

Most of the studied area is formed from an anomalous structure and regeneration patches are abundantly found at the habitat level [26].

Three distinct plant communities can be distinguished in Gorazbon district which include:

1) Querceto-Carpinetum, 2) Fageto-Carpinetum, 3) Fagetum hyrcanum.

The highest level of habitat is from this community, and it is found mostly in the northern steep and humid hillsides and there are very good quality beeches. The amount of growth in these habitats is good and the Fagus orientalis Lipsky in this community have a relatively good altitude.

In this community, eastern beech with an average volume of 187 cubic meters per hectare and more than 74 percent; hornbeam with 21 cubic meters per hectare and 8 percent; and pallet with 18 cubic meters per hectare and 7 percent comprise the highest percentage of habitat surface species. Other tree species in Gorazbon district consist of Prunus avium, Acer cappadocicum, walnut, Quer- 
cus castaneifolia, tilia, Alnus subcordata, Diospyros lotus, Fraxinus excelsior, Parrotia persica, Sorbus torminalis, Taxus baccata and shrub species. Moreover, woody plants such as frangula, Mespilus germanica, Lycopersicon hirsutum, hawthorns, butcher's broom, raspberries, sweet-amber and Hedera helix can be mentioned [27].

\subsection{Research Method}

The land harvesting relevant to this study was conducted in the summer of 2015 in the natural habitats of eastern beech in vegetated Hirkani area.

First, in order to harvest one hundred percent of regeneration patches using GPS and circling forest in the study area, regeneration patches were identified and the area around the patches was marked and located as a point. In this research, regeneration patches are known to have clear spaces with a minimum surface area of 100 square meters and to have seedlings created by the death of one or more trees.

In order to compare and accurately analyze the patches and the possibility of quantification of the metrics at the class level, the patches are categorized and coded based on the height of seedlings established in each patch and canopy is categorized and coded to four classes. They include:

1) Patches with seedlings longer than $50 \mathrm{~cm}$ (code $A)$;

2) Patches with seedlings shorter than $50 \mathrm{~cm}$ (code $B$ );

3) Patches under the closed canopy (90\% (code C));

4) Patches under the open canopy (code D).

In this step, in addition to recording the coordinates of the patches, the environmental properties of the patches such as slope, direction and height were also taken. Then they were converted to the surface by transferring to the computer environment and using appropriate software. Finally, each patch was identified as a polygon with different shapes. In the next stage of the conclusion, the overlapping and merging of the regeneration maps were taken and the direction map, distribution map and distribution of regeneration patches were obtained in different geographical directions.

\subsection{Data Analysis}

Fragstats software was used to quantify the metrics in order to analyze spatial metrics of regeneration patches. The software quantifies the metrics at three levels.

1) At the level of each patch, 2) at the level of each class, and 3) at the whole level of landscape.

In this research, the analysis of metrics was carried out at two levels of class and landscape.

\subsubsection{Analysis of Metrics at the Class Level}

The analysis of metrics at this level was conducted based on the calculation of each metric of class level for all four classes of patches in different directions. In the following, some of the metrics used at this level are defined as follows: 
The number of patches (NP): This metric quantifies the number of patches per class.

The percentage of the landscape (PLAND): It measures the proportion of the percentage of each patch in each class relative to the different patches in the other classes.

Patch Density (PD): these metric shows the number of patches per surface area for each class of patches and allows comparisons among different classes.

Largest patch index (LPI) shows the largest patches in each class.

Mean patch area (Area_MN) measures the average size of patches at the class level.

Large scale integration (LSI) shows the complexity rate and different shapes of patches at the level of each class.

The average metric of distance between the patches (ENN_MN) is to measure the mean, weighted average, mean, and range of variations, standard deviation, and the coefficient of variation of the distance between the patches.

\subsubsection{Analysis of Metrics at the Level of the Landscape}

The analysis of metrics at this level for all of the patches was studied regardless of their classification in different geographical directions in the whole region. At this level, in addition to calculating the metrics given at the level of the class (the difference is that all the metrics were calculated for all the patches this time), Simpson diversity index (SIDI) and Shannon diversity index (SHDI) were used to calculate diversity and uniformity of patches. Simpson and Shannon metrics are among the most important diversity metrics for the study of regeneration patches. Simpsion metric is more sensitive to the most abundant patches and Shannon metric is more sensitive to the rarest patches.

When the amount of homogeneity of the number is one, that is, the landscape is very diverse. When it tends to zero, the diversity of the landscape is reduced. The closer the amount of variance metrics is to one, the less the amount of diversity is. As much as it approaches zero, the amount of diversity decreases.

In this research, ArcGIS, FRAGSTATS, SPSS and Excel softwares were used.

In the following, the description and distribution of the metrics taken from McGarigal and Marks (1995) and their calculation in Fragstats software by interpreting the mathematical equations for each of the metrics are summarized in Table $1[20]$.

\section{Results}

\subsection{Results of the Analysis of Metrics at the Class Level}

In this study, totally 692 regeneration patches were identified in different directions (Table 2). At the level of the class, the highest number of patches was associated with patches with seedlings longer than $50 \mathrm{~cm}$ (223 cases) in the southern directions and the lowest number of patches was associated with patches with seedlings under open canopy and seedlings shorter than 50 centimeters ( 5 cases) in the eastern directions. 
Table 1. Metrics used in this study (McGarigal and Marks, 1995)**.

\begin{tabular}{|c|c|c|c|}
\hline Ranges & Unit & Description & Formulas and acronyms \\
\hline $\mathrm{NP}>0$ & NO Unit & Number of Patches & $N P=n$ \\
\hline $0<$ PLAND $\leq 0$ & Percentage & Percentage of Landscape & $P L A N D=P_{i}=\frac{\sum_{j=1}^{a} a_{i j}}{A}(100)$ \\
\hline $\mathrm{PD}>0$ & Meter in 100 ha & Patch Density & $P D=\frac{n_{i}}{A}(10,000)(100)$ \\
\hline SHDI $\geq 1$ & NO Unit & Shannon's Diversity Index & $S H D I=-\sum_{i=1}^{m}\left(P_{i} \ln p_{i}\right)(100)$ \\
\hline $0 \leq \mathrm{SIDI} \leq 1$ & NO Unit & Simpson's Diversity Index & $S I D I=1-\sum_{i=1}^{s} P i^{2}$ \\
\hline $0<\mathrm{LPI}<100$ & Percentage & Largest Patch Index & $L P I=\frac{n\left(a_{i j}\right)}{A}(100)$ \\
\hline LSI $\geq 1$ & NO Unit & Landscape Shape Index & $L S I=\frac{e_{i}}{\min e_{i}}$ \\
\hline $\mathrm{TA}>0$ & ha & Total Area & $T A=A\left(\frac{1}{10000}\right)$ \\
\hline $0<\mathrm{RPR}<100$ & Percentage & Patch Richness Density & $R P R=\frac{m}{m_{\max }}(100)$ \\
\hline $\mathrm{CA}>0$ & ha & Total (Class) Area & $C A=\sum_{j=1}^{n} a_{i j}\left(\frac{1}{10,000}\right)$ \\
\hline Area_MN $>0$ & ha & metrics mean Patch Area & Area_MN $_{-}=\frac{\sum_{j=1} x_{i j}}{n_{i}}$ \\
\hline ENN_MN $>0$ & Meter & Euclidean Nearest Neighbor Distance- Mean & $E N N_{-} M N=\frac{\sum_{i=1}^{m} \sum_{i=n}^{n} x_{i j}}{N}$ \\
\hline
\end{tabular}

${ }^{*}$ In Table 1, the letter A used in PD and LPI and TA indices is total area of the landscape per square meter and the letter $e_{i}$ is the total length of the environment or edge of the patches of class $i$ and min $e_{i}$ is the minimum edge length or the patch environment in the class $i$ in the index LSI. Also, $m$ is the number of type of patches in landscape and $m_{\max }$ shows the total number of patches in the landscape in RPR index. $p_{i}$ which is the proportion of the landscape is occupied by $i$ patch and $a_{i j}$ is the area $\left(\mathrm{m}^{2}\right)$ of $i j$ patch.

Table 2. The results of the analysis s of the metrics at the class level and among different geographical directions.

\begin{tabular}{|c|c|c|c|c|c|c|c|c|c|c|c|c|c|c|c|c|c|c|c|c|}
\hline \multicolumn{20}{|c|}{ The results analysis metrics Fragstats } & \multirow{3}{*}{$\begin{array}{l}\text { geographical different } \\
\text { aspects }\end{array}$} \\
\hline \multicolumn{4}{|c|}{$(\mathrm{NP})^{+}$} & \multicolumn{4}{|c|}{$(\mathrm{LSI})^{+}(>0)$} & \multicolumn{4}{|c|}{$(\mathrm{LPI})^{+}(\mathrm{ha})$} & \multicolumn{4}{|c|}{$(\mathrm{PLAND})^{+}(\%)$} & \multicolumn{4}{|c|}{$(\mathrm{PD})^{+}$(m $\left.100 \mathrm{ha}\right)$} & \\
\hline $\mathrm{C}^{*}$ & $\mathrm{D}^{*}$ & $A^{*}$ & $\mathrm{~B}^{*}$ & $\mathrm{C}^{*}$ & $\mathrm{D}^{*}$ & $\mathrm{~A}^{*}$ & $\mathrm{~B}^{*}$ & $\mathrm{C}^{*}$ & $\mathrm{D}^{*}$ & $A^{*}$ & $\mathrm{~B}^{*}$ & $\mathrm{C}^{*}$ & $\mathrm{D}^{*}$ & $\mathrm{~A}^{*}$ & $\mathrm{~B}^{*}$ & $\mathrm{C}^{*}$ & $\mathrm{D}^{*}$ & $\mathrm{~A}^{*}$ & $\mathrm{~B}^{*}$ & \\
\hline 25 & 21 & 25 & 21 & 6 & 5.3 & 5.8 & 5.5 & 0.1 & 0.1 & 0.1 & 0.1 & 1.4 & 1.3 & 1.3 & 1.4 & 32.4 & 27.5 & 32.8 & 27.5 & North \\
\hline 209 & 136 & 223 & 36 & 17.8 & 14.1 & 18.3 & 13.4 & 0.05 & 0.03 & 0.05 & 0.03 & 2.6 & 1.6 & 2.8 & 1.4 & 46.8 & 30.5 & 50 & 27.3 & South \\
\hline 16 & 5 & 16 & 5 & 4.8 & 2.7 & 4.8 & 2.7 & 0.3 & 0.3 & 0.3 & 0.3 & 1.6 & 0.7 & 1.6 & 0.7 & 36.6 & 19.9 & 36.6 & 19.9 & East \\
\hline 120 & 70 & 125 & 65 & 12.8 & 10.07 & 13.2 & 3.3 & 0.1 & 0.09 & 0.1 & 0.1 & 3.2 & 1.2 & 2.8 & 1.7 & 71.2 & 41.5 & 74.2 & 31.6 & West \\
\hline 53 & 37 & 59 & 31 & 3.9 & 3.5 & 4.3 & 3.2 & 0.2 & 0.3 & 0.3 & 0.1 & 2.4 & 1.6 & 2.9 & 1.2 & 26.5 & 69.2 & 31.3 & 16.8 & Flat(edge) \\
\hline 423 & 269 & 448 & 158 & 4.45 & 35.9 & 46.6 & 34.3 & 0.9 & 0.9 & 1.03 & 0.8 & 11.4 & 6.7 & 11.5 & 6.6 & 241.1 & 141.2 & 252.1 & 123.3 & Total \\
\hline
\end{tabular}

${ }^{*} \mathrm{~A}$ means patches with seedlings longer than $50 \mathrm{~cm}, \mathrm{~B}$ patches with seedlings shorter than $50 \mathrm{~cm}, \mathrm{C}$ regeneration patches under open canopy and $\mathrm{D}$ regeneration patches under closed canopy. ${ }^{+} \mathrm{PD}$ is the density of each class of patches at the class level (meter per 100 hectares). PLAND is the percentage of coverage level for each class at the class level. LPI is the index of biggest patches at the class level (hectare). LSI is the index of standard form of patches at the class level (no unit). NP is the number of patches per class at the class level. 
The relative frequency of each category of patches was calculated in different directions and the percentage of patches with seedlings longer than $50 \mathrm{~cm}$ and patches under closed canopy in most directions is more than the other types (Table 2). Patch density has the highest amount for patches with seedlings longer than $50 \mathrm{~cm}$ (74.25 m per 100 hectares), and patches with seedlings under closed canopy (71.28 m per 100 hectares) have the highest amount in the western and southern directions relatively. The lowest density of patches is related to patches with seedlings longer than $50 \mathrm{~cm}$ (16.78 m per 100 hectares) and in flat areas.

The results of the metric of the largest patch size in the class of patches with seedlings longer than $50 \mathrm{~cm}$ and patches under open canopy are more than those of the other classes. The results of the metric of the largest patch size indicate that the largest size of patches are related to patches with seedlings under closed canopy and with seedlings longer than 50 centimeters $(0.35 \mathrm{ha})$ in the eastern and flat directions. The smallest patch which has an area of 300 square meters $(0$, $03 \mathrm{ha}$ ) and is related to patches with seedlings shorter than $50 \mathrm{~cm}$ and patches under open canopy are located in the southern directions.

According to the patch shape metric, the most complex patches in terms of the shape are among the patches with seedlings longer than 50 centimeters (18.36) in the southern directions and the simplest patches in terms of the shape are the patches under the open canopy and the patches with seedlings shorter than 50 centimeters are in the eastern direction. An increase in the metric of the patches' shape means increased incidence and complexity in the form of patches (Table 2).

The distance of average metric between regeneration patches (Figure 2) at the class level shows the maximum distance between patches relevant to patches with the seedlings shorter than $50 \mathrm{~cm}$ and the patches under the closed canopy $(622.15 \mathrm{~m})$ in the eastern direction indicating that the least average distance between patches is related to patches with seedlings longer than $50 \mathrm{~cm}(68.03 \mathrm{~m})$ in the southern direction. In the northern directions, the maximum average distance between the patches $(197.69 \mathrm{~m})$ is related to the patches under open canopy and the minimum average distance $(116.45 \mathrm{~m})$ is related to the patches under the closed canopy (Figure 2). In the southern directions, the maximum and minimum average distances between the patches were $(89.33$ and $68.03 \mathrm{~m}$ ) respectively among the patches with the seedlings shorter than 50 centimeters and longer than 50 centimeters.

The maximum and minimum average distances between the patches in the eastern directions were $(622.15$ and $264.12 \mathrm{~m})$ respectively related to the patches with open canopy and the patches with seedlings shorter than $50 \mathrm{~cm}$ and the minimum is related to the patches with the open canopy and the patches with seedlings longer than 50 centimeters.

In the western directions, the greatest distance was observed for the patches with seedlings shorter than $50 \mathrm{~cm}(148.49 \mathrm{~m})$ and the least distance was for patches under closed canopy $(87.53 \mathrm{~m})$. 
The maximum distance between the patches in the flat areas with the value of $200.89 \mathrm{~m}$ was related to patches with the seedlings shorter than $50 \mathrm{~cm}$ and the minimum distance with the value of $133.40 \mathrm{~m}$ was related to the patches with seedlings longer than $50 \mathrm{~cm}$ (Figure 2). The average metric of area of patches at the level of the class (Figure 3 ) shows that the maximum area of the patches is between 3 and $4 \mathrm{R}$ (Figure 3 ).

The maximum and minimum mean areas of the patches are located in the northern directions ( 0.05 and 0.04 hectares) and are respectively related to the patches under open canopy and the patches under closed canopy. In the southern directions, most of the patches have an area of about $5 \mathrm{R}$. The average area of the patches in the eastern directions is from 2.5 to $3 \mathrm{R}$ respectively and it is variable for patches under the closed canopy and the patches with seedlings shorter than 50 $\mathrm{cm}$. In western directions, the maximum average area of the patches $(4.5 \mathrm{R})$ is related to patches with the closed canopy and the minimum mean area of patches ( 3 $\mathrm{R}$ ) is related to the patches under the open canopy (Figure 3). The average area of most of the patches in undirectional and flat areas is about $4 \mathrm{R}$ (Figure 3 ).

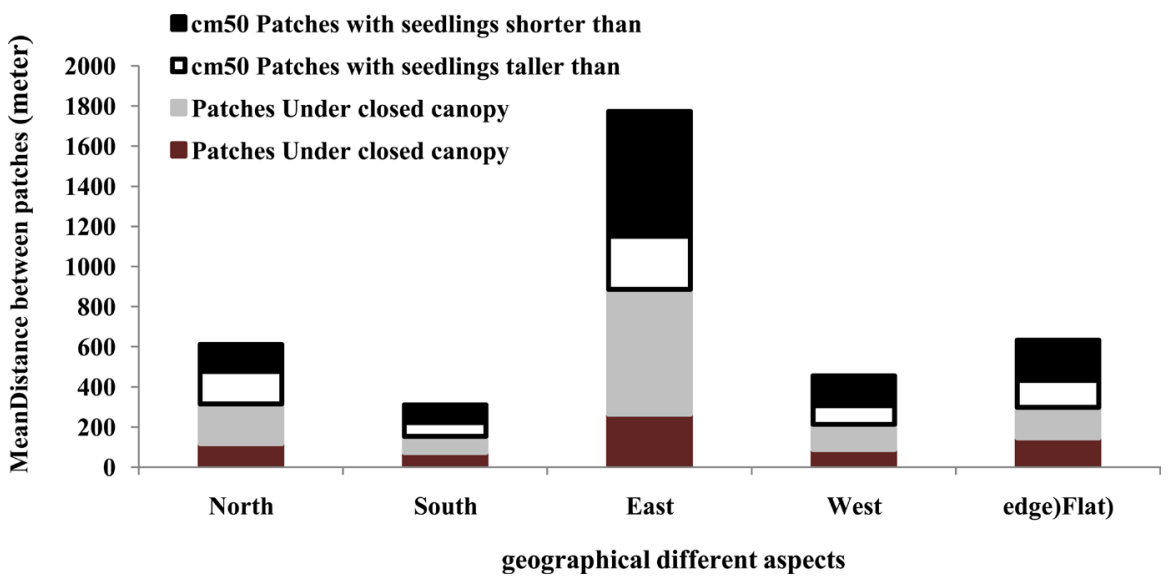

Figure 2. Analysis results of the distance average metric between regeneration patches in different geographical directions.

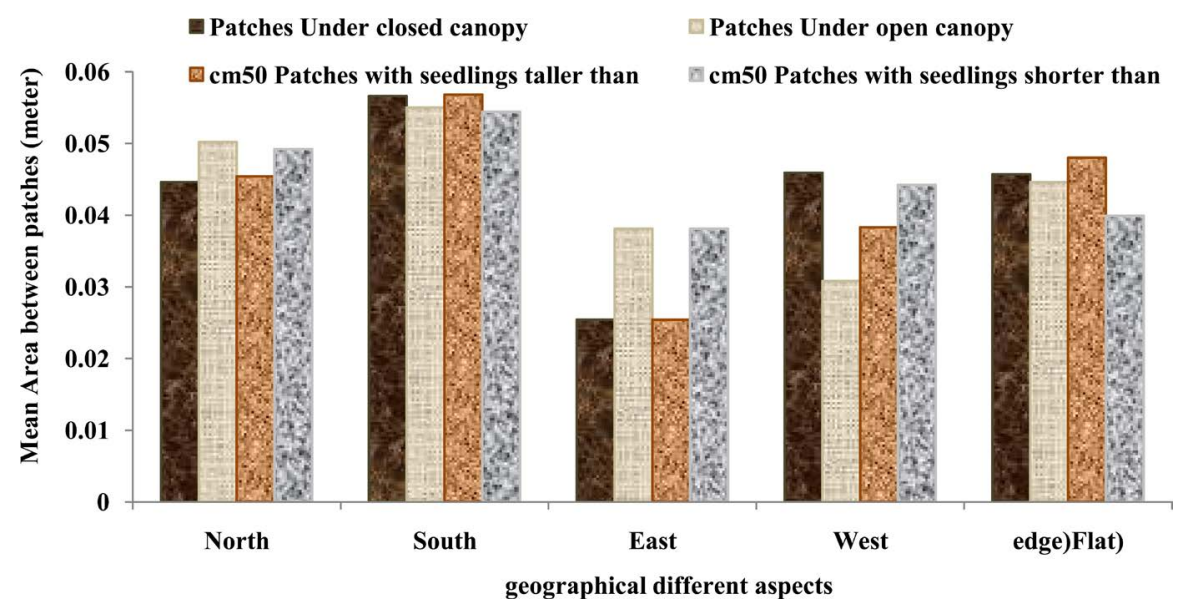

Figure 3. Analysis results of the average metric of area of regeneration patches in different geographical directions. 


\subsection{The Results of the Analysis of Metrics at Landscape Level}

At this level of study, the analysis of the spatial metrics of regeneration patches was performed regardless of the category or classification of patches and all the patches in each of the geographical directions were analyzed (Table 3). According to the total area metric, the total level of each direction of Gorazbon district was determined. The highest level of Gorazbon district is from the southern directions ( 445.33 hectares). The lowest level is related to the eastern direction (25/12 hectares). In total, the total area of the study area (Gorazbon district) was calculated 813.04 hectares.

In total, there are 692 regeneration patches located in Gorazbon district, the highest number of which are located in the southern, western directions, flat regions (edges), northern and eastern directions (south 345, west 190, flat regions 90 , north 46, and east 21) (Table 3).

Patch density metric shows the proportion of the density patches according to the level of each direction. The more the proportion is, the more the patch density is in that direction and the better regeneration there is. The highest patch density $(112.86 \mathrm{~m} / 100$ hectares) is observed in western directions and the lowest density ( $60.43 \mathrm{~m} / 100$ hectares) is observed in northern directions.

Based on the metric of the largest patch size, the largest patches with the value of 0.34 and 0.22 hectares are located in the eastern directions and flat areas respectively. The smallest amount of the metric of the largest patch size is in the southern directions with an area of 0.05 hectares. Northern directions $(0.18$ hectares) and western directions ( 0.13 hectares) are in intermediate mode.

The metric of complexity of the patch shape (without unique LSI) shows the most complexity of the shape of the patches in the western (24.90), southern (18.24), flat regions (15.55), eastern (11.82) and the northern (11.46) directions respectively (Table 3 ). Patch richness metric shows the highest richness related to the types of patches in the northern directions $(7.96 \%)$ and the lowest amount in the eastern direction $(0.44 \%)$. This metric shows a percentage of different

Table 3. The results of the analysis of the metrics at the level of the landscape and among different geographical directions.

\begin{tabular}{ccccccccc}
\hline \multicolumn{7}{c}{ metrics in the level landscape } & different geographical directions \\
\cline { 1 - 7 } TA & NP & PD & LPI & LSI & PRD & SHDI & SIDI & North \\
\hline 76.1 & 46 & 60.4 & 0.1 & 11.4 & 7.9 & 0.69 & 0.49 & South \\
445.8 & 345 & 77.3 & 0.05 & 18.2 & 5.4 & 0.65 & 0.45 & East \\
25.1 & 21 & 83.5 & 0.3 & 11.8 & 0.4 & 0.6 & 0.4 & West \\
168.3 & 190 & 112.8 & 0.1 & 24.9 & 2.6 & 0.6 & 0.4 & Flat(edge) \\
97.6 & 90 & 92.1 & 0.2 & 15.5 & 2.04 & 0.6 & 0.4 & Total \\
813.04 & 692 & 426.4 & 0.9 & 81.9 & 18.5 & 3.2 & 2.2 &
\end{tabular}

TA (hectare) is the area of each direction, NP the number of total patches in each direction, PD the total density of the patches at the level of each direction (m per 100 hectares), LPI (hectare) the highest patch index at the level of each direction, LSI (no unit) patch shape index in each direction, PRD (percentage) patch richness index, SHDI (no unit) Shannon diversity metric, SIDI (no unit) Simpson diversity metric. 
grades of the patches in different directions. The southern (5.46\%), the western $(2.62 \%)$ directions and the flat regions $(0.24 \%)$ have intermediate modes.

Shannon variation metric is more sensitive to the rarest patches. As you can notice in Table 3, the most various and rare patches (0.69) are in the northern, western (0.66), southern (0.64), eastern (0.62) directions and flat areas (0.61) respectively.

Simpson diversity metric is more sensitive to the frequency. Based on the results of Simpson diversity metric (Table 3), the highest frequency (0.49) of the patches relative to the surface was observed in the northern directions and the lowest value (0.42) is related to the flat regions. Western (0.46), southern (0.45) and eastern directions (0.43) have respectively intermediate modes.

TA (hectare) is the area of each direction, NP the number of total patches in each direction, PD the total density of the patches at the level of each direction (m per 100 hectares), LPI (hectare) the highest patch index at the level of each direction, LSI (no unit) patch shape index in each direction, PRD (percentage) patch richness index, SHDI (no unit) Shannon diversity metric, SIDI (no unit) Simpson diversity metric.

In total, the minimum and maximum distance between the patches in all the directions of Gorazbon district (totally four classes) varies from 39 to 520 meters at the level of the landscape. The results of this metric show the least average distance $(75.5 \mathrm{~m})$ in the southern directions and the most average distance $(349.3 \mathrm{~m})$ in the eastern directions (Figure 4). The average distance metric between the patches calculated the average distance of the regeneration patches in the western directions at about $100 \mathrm{~m}$, and in the northern directions and the flat regions (edges) about $150 \mathrm{~m}$ (Figure 4). In total, the minimum and maximum areas of the patches at the total level of landscape (all directions) are 1.5 and $35 \mathrm{R}$ respectively. Most of the average area of the patches at the level of landscape is about 4 - 5 R (Figure 4(b)).

The average metric of patches area demonstrates the highest average area of the patches at the level of landscape. They were respectively related to southern (0.5 hectares), northern (0.47 hectares), flat regions (edges) (0.4 hectares), west

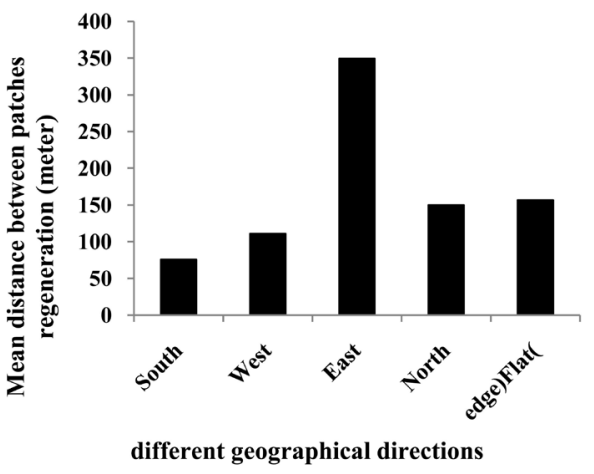

(a)

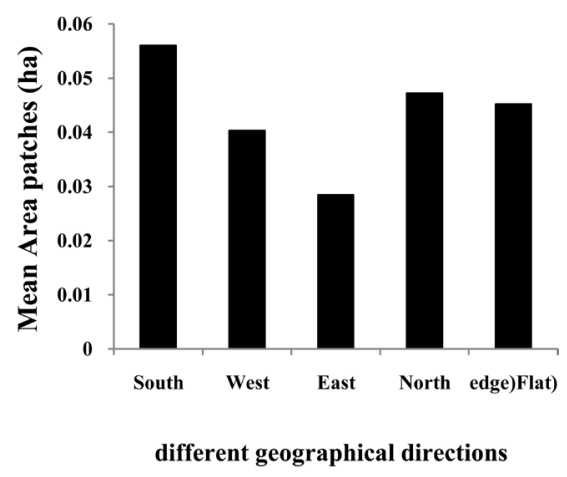

(b)

Figure 4. Analysis results of the average metric of distance (a) and area (b) between the patches in different geographical directions. 
ern (0.4 hectares) and eastern directions (0.2 hectares) (Figure 4(b)).

\section{Conclusions}

The studies which have been done in Iran with regard to regeneration patches have been more qualitative and they take the quantitative and spatial properties of patches into account less. Limited research carried out has used more than one or two indices for introduction and the analysis of patches [28]. However, in the present research, several metrics have been taken to quantify the spatial properties of the patches and its interpretation with the landscape ecology approach [29]. In fact, in this study the principles of the landscape ecology, a subset of ecology and geography; have been used to distribute and to disperse patches in different geographical directions, to change and to interpret in each direction.

Geographical directions can act as a limiting factor for regeneration and an exacerbation one by creating both ecological and hydrological conditions in forest ecosystems [3]. On this basis, it can be admitted that the density of regeneration patches at the level unit in a natural forest can be a suitable criterion for determining the degree of interference and pristine in the natural mass [22]. The spatial pattern of tree dispersion in forest masses is a mosaic reflection of a complex environment, which implies environmental disturbances on a micro scale and the chance of success of different species over time relies on the characteristics of the life history of each of them [30].

The results of the metrics used in this study show that they have the most suitable variety and dispersion of the patches in the northern directions compared to the other directions. That is probably due to fertility and enough humidity in the northern directions compared to the other directions [21] [31]. Considering the rate of changes in the metrics in different geographical directions, it can be concluded that humidity, light, human interferences and proper dispersion of mother stocks have significant effects on the dispersion pattern of patches. These results are in agreement with the results of researches of Mirzaei et al. (2007), in which a study was conducted in Zagros forests to compare the natural regeneration density of wood species in relation to physiographic and soil factors. The researchers found out that the regeneration density of the species in the region shows different reactions to physiographic factors [32].

In this study, the researchers studied the different metrics of regeneration patches in different directions and they concluded that the percentage of patches with the seedlings longer than $50 \mathrm{~cm}$ and the patches with closed canopy in most directions was more than that of the other classes. It indicates that most of the seedlings cross the grazing horizon due to the closeness of the crown of trees in most of the patches. It can be concluded that the regeneration has established in the forest and we should consider a suitable cultivate and corrective project in the canopy understory. In this study, it was determined that the relative frequency of patches in the total unit level of the studied area (landscape level) is 
8.3\%. These results are consistent with the results of Mataji et al. (2008), which estimates the frequency in eastern Fagus orientalis Lipsky 9\%. These results are also confirmed by Sefidi et al. (2011), which is estimated to be $9.3 \%$ on the Eastern Fagus orientalis Lipsky in northern forests of Iran [19] [28].

Due to the low ratio of the area of northern directions, this direction has the highest density of patches. In the northern directions, most classes (longer than 50 centimeters, shorter than 50 centimeters, closed canopy and open canopy) occupy the same percentage. This is due to the proper conditions in the northern directions and the rapid establishment and growth of seedlings, which greatly contributes to the regeneration establishment.

As the results of this research show, moisture, in addition to light, is also a limiting factor in the formation of patches and the growth of seedlings greatly influences forest regeneration.

As it was observed in this study, most of the patches with closed canopy have seedlings longer than $50 \mathrm{~cm}$ [33]. Therefore, with regard to the shade-loving seedlings of the beech and less evaporation in the patches with closed canopy, the conditions for early and better establishment of these seedlings have been increased and these conditions in the northern direction are more appropriate due to the hillside shading and more rainfall. Hence, according to the results obtained from the metrics used in this study, the distribution and dispersion of patches in the northern directions are more suitable due to the reducing the limitation of regeneration patches relative to the other directions [11], and it shows a more suitable pattern in terms of the variety, distribution and dispersion of various patches.

In this research, the results of different metrics showed that the highest ecological stability in the distribution, dispersion, diversity and establishment of regeneration patches was observed in the western, southern and northern directions respectively, and the least stability was observed in the eastern directions.

The results of this study are in agreement with the results of Jalali and Hosseini (2000), which showed that the regeneration has been done better in southern and southwestern hillsides [22]. Based on the results of measured metrics, it was observed that each direction has its own pattern, but the pattern of dispersion and structure of the patches in the northern directions has better distribution and uniformity than the other directions. It can be considered as a natural regeneration pattern to follow the natural processes and the continuation of the sustainability and survival of forest resources.

According to the results of the area of the southern and western hillsides, it can be seen that the highest forest level in the whole landscape of Gorazbon district belongs to the southern and western directions. In other words, the southern and western directions form the highest level of forests in the district. This suggests the sensitivity of marking and forest management at mass level in these directions.

According to the findings of Mousavi et al. (2003), the best size of patches for regeneration in northern Iran's Fagus orientalis Lipskyis patches of $4-5$ R. The 
results of the analysis of average metrics of patch size and the size of the largest patch in different directions showed that the average area of the patches varies from 4 to $5 \mathrm{R}$ in most directions [34]. The results of this study, in addition to being consistent with the results of Moussavi et al. (2003), is also in agreement with Emborg et al. (2000), study results, in which there was a similar research in Danish Fagus orientalis Lipsky and they showed that the minimum area of the cavity was 384 and the maximum was 1467 square meters [34] [35].

According to an analysis of forestry, on the edges (flat regions), the possibility of the formation of larger patches is greater due to winding, turbulence and instability of the edges [21]. The results are consistent with the findings of Mirkazemi (1993), which stated that regeneration patches on the edges are better and larger than the ones in the other places [18]. The shape of the patches can be important in determining the type of turbulence and the natural pattern of the formation of patches.

The results of the patch shape metric indicate that most of the shape of patches in the study area follow an unconventional and multifaceted structure and have no fixed forms. These results are consistent with Hojjati (1999), Amanzadeh et al. (2006). They concluded that the shape of the patches does not follow the regular geometric form. These results are also consistent with Gagnon et al., 2004, expressing that the shape of the patches is more irregular and less circular [25] [36]. According to the results of this study, patches initially have the most complexity of the patch shape and the complexity is reduced with the evolution and aging of the patch.

The patch size, the average size of the patch and the patch shape has a direct effect on the light regulation for planning forestry processes.

These metrics also play a key role in creating instable inconsistencies and turbulences caused by the wind influence on the inside of the patches at the level of the forest and it should be considered in planning sustainable forest management. Considering that the most complex patches in terms of shape are in western (24.9) and southern (18.2) directions and that human use are more in these directions due to the hillside warming during the year (livestock and fuel), it can be concluded that the human interfering factor is effective in the formation of these patches [21]. According to the results of the average distance metric between the patches, the dispersion of patches in the southern and western directions and pile flat regions are random in the eastern direction and are uniform in the northern direction. The results of this study are consistent with findings of Mataji et al. (2008), who stated that the dispersion pattern of the patches in the eastern Fagus orientalis Lipsky is random and uniform [28].

From the ecology viewpoint, the patches can be considered as sections and passages for the establishment of plant species with different ecological requirements as well as the species of animals that are useful and effective for preserving and balancing forest ecosystem. Hence when the distance between the patches is less, in addition to ensuring the establishment of regeneration, the established passages and sections are of higher quality and the movement of the species in 
the forest landscape context will be easier and thus the ecosystem sustainability will be provided in order to achieve a sustainable management of the entire forest functions.

Based on the results of this study, physiographic factors are recognized the most important dynamic factors in the spatial structure of forest ecosystems, so Zahedi and Amiri (2002) point out geographical directions the most important factor of this separation [37].

Finally, it should be noted that by using a combination of different metrics of the landscape and by controlling its changes over time, one can map out the structural changes and the dispersion pattern of regeneration patches and the effects of various activities on it. It was possible to prioritize corrective actions and how to implement it in different forest areas by using this map. In addition, using the landscape criteria at the mass level and each regeneration patch, it is possible to predict its internal situation in terms of complexity of the structure and thus its survival and stability.

It is recommended that the managers use the landscape metrics to analyze the changes and dynamism of the pattern of regeneration patches in forest ecosystems over time and in different ecosystems by taking into account the effects of other environmental factors and human activities on the area.

\section{References}

[1] Gabriel, A.G. and Mangahas, T.L.S. (2017) Indigenous People's Contribution to the Mitigation of Climate Variation, Their Perception, and Organizing Strategy for Sustainable Community Based Forest Resources Management in Caraballo Mountain, Philippines. Open Journal of Ecology, 7, 85-100.

http://www.scirp.org/journal/PaperInformation.aspx?paperID $=73888$ https://doi.org/10.4236/oje.2017.72007

[2] Crow, T.R. (2008) Managing Forest Landscapes for Climate Change. In: Lafortezza, R., Chen, J., Sanesi, G. and Crow, T.R., Eds., Patterns and Processes in Forest Lanscapes: Multiple Use and Sustainable Management. Springer Science and Business Media B.V., New York, 33-43. https://link.springer.com/chapter/10.1007/978-1-4020-8504-8 1\#page-1

[3] Manju, A. and Rachana, P. (2015) Conservation of Forestry Biomass with the Use of Alternative Resource. Open Journal of Ecology, 5, 87-109. http://file.scirp.org/Html/1-1380337 55277.htm https://doi.org/10.4236/oje.2015.54009

[4] Gabriel, A.G., Claudio, E.G. and Bolisay, F.A. (2017) Saving Duping a Watershed in Gabaldon, Nueva Ecija Philippines: Insights from Community Based Forest Management Model. Open Journal of Ecology, 7, 140-157. https://www.scirp.org/Journal/PaperInformation.aspx?PaperID=74348 https://doi.org/10.4236/oje.2017.72011

[5] Inouye, B.C. (1999) Integrating Nested Spatial Scales: Implications for Coexistence of Competitors on a Patchy Resource. Journal of Animal Ecology, 68, 150-162. https://doi.org/10.1046/j.1365-2656.1999.00272.x

[6] Jalali, G.A. (1982) Natural Regeneration of Beech in the Lower Section Fagetum Darbklay North Surrey Area. Master of Science's Thesis, Tehran University Faculty of Natural Resources, Tehran. 
[7] Allen, T.F. and Starr, T.B. (1982) Hierarchy: Perspectives for Ecological Complexity. The University of Chicago Press, Chicago.

https://www.abebooks.com/book-search/title/hierarchy-perspectives-for-ecologicalcomplexity/

[8] Kotwalp, P.C., et al. (2008) Ecological Indicators: Imperative to Sustainable Forest Manangement. Indian Institute of Forest Management, P.O.BOXNO.357, Nehru Nagar, Bhopal, 462003.

[9] Dale, V.H., Joyce, L.A., McNulty, S. and Neilson, R.P. (2000) The Interplay between Climate Change, Forests, and Disturbances. The Science of the Total Environment, 262, 201-204.

http://www.sciencedirect.com/science/article/pii/S0048969700005222 https://doi.org/10.1016/S0048-9697(00)00522-2

[10] Bouchard, M., Kneeshaw, D. and Bergeron, Y. (2008) Ecosystem Management Based on Large-Scale Disturbance Pulses: A Case Study from Sub-Boreal Forests of Western Quebec (Canada). Forest Ecology and Management, 256, 1734-1742. https://www.researchgate.net/publication/223741437 https://doi.org/10.1016/j.foreco.2008.05.044

[11] Ullah, M., Khan, A.A., Saleem, A., Saeed, S. and Wahab, U. (2015) Assessment of Forest Growing Stock of Timergara Forest Subdivision, Dir Lower Forest Division. Open Journal of Ecology, 5, 537-543. http://file.scirp.org/Html/1-1380419 60986.htm https://doi.org/10.4236/oje.2015.511044

[12] Rivas, M., Filippini, J.M., Cunha, H., Hernández, J., Resnichenko, Y. and Barbieri, R.L. (2017) Palm Forest Landscape in Castillos (Rocha, Uruguay): Contributions to the Design of a Conservation Area. Open Journal of Forestry, 7, 97-120. http://www.scirp.org/journal/PaperInformation.aspx?PaperID=74784 https://doi.org/10.4236/ojf.2017.72007

[13] Hamann, A. and Wang, T. (2006) Potential Effects of Climate Change on Ecosystem and Tree Species Distribution in British Columbia. Ecology, 87, 2773-2786.

http://onlinelibrary.wiley.com/doi/10.1890/0012-9658(2006)87[2773:PEOCCO]2.0. $\underline{\mathrm{CO} ; 2 / \text { full }}$ https://doi.org/10.1890/0012-9658(2006)87[2773:PEOCCO]2.0.CO;2

[14] Reza, M.I.H. and Abdullah, S.A. (2016) Developing Ecosystem Maps Using EcoGeological Information for the Sustainable Management of Natural Resources. Open Journal of Ecology, 6, 343-357.

http://file.scirp.org/Html/6-1380511 66516.htm https://doi.org/10.4236/oje.2016.66033

[15] Beaumont, L.J., Hughes, L. and Poulsen, M. (2005) Predicting Species Distributions: Use of Climatic Parameters in BIOCLIM and Its Impact on Predictions of Species' Current and Future Distributions. Ecological Modelling, 186, 250-269. https://doi.org/10.1016/j.ecolmodel.2005.01.030

[16] Rodrigues, P.J.P., Iguatemy, M.A. and Nascimento, M.T. (2014) Does Linear Canopy Openings in Lowland Atlantic Tropical Forest Cause Edge Effects on Seedling Communities? Open Journal of Ecology, 4, 945-949. http://file.scirp.org/Html/1-1380301 51431.htm https://doi.org/10.4236/oje.2014.415078

[17] Drößler, L. and Von Lüpke, B. (2005) Canopy Gaps in Two Virgin Beech Forest Reserves in Slovakia. Journal of Forest Science, 51, 446-457.

[18] Mir-Kazemi, C.Z. (1993) Investigated Determine Cycle of the Seed Yields Beech Fagus orientalis Lipsky Pilgrimage in Gorgan. Master of Science's Thesis, Department of Natural Resources, Tehran University, Tehran. 
[19] Sefidi, K., Marvie-Mohadjer, M.R., Etemad, V. and Copenheaver, C.A. (2011) Stand Characteristics and Distribution of a Relict Population of Persian Ironwood (Parrotia Persica C.A. Meyer) in Northern Iran. Flora, 206, 418-422.

http://www.sciencedirect.com/science/article/pii/S0367253010001635 https://doi.org/10.1016/j.flora.2010.11.005

[20] McGarigal, K. and Marks, B.J. (1995) Fragstats: Spatial Pattern Analysis Program for Quantifying Landscape Structure. USA: US Department of Agriculture, Forest Service, Pacific Northwest Research Station, 122 p. http://www.scirp.org/(S(lz5mqp453edsnp55rrgjct55))/reference/ReferencesPapers.a spx?ReferenceID $=580927$ https://doi.org/10.2737/PNW-GTR-351

[21] Karami, A. (2011) Investigation on the Metrics of the Forest Regeneration Patches for Sustainable Forest Management (SFM). Master of Science's Thesis, Tehran University Faculty of Natural Resources, Tehran.

[22] Jalali, S.G. and Hosseini, S.M. (2000) Evaluation the Effects Various Factors on the Natural Breeding Quercus infectoria Species in Surdar Noor. Of Daneshvar Journal, 31, 69-74. http://fa.journals.sid.ir/ViewPaper.aspx?id=27955

[23] Yimer, F., Ledin, S. and Abdelkadir, A. (2006) Soil Property Variations in Relation to Topographic Aspect and Vegetation Community in the South-Eastern Highlands of Ethiopia. Forest Ecology and Management, 232, 90-99. http://www.scirp.org/(S(i43dyn45teexjx455qlt3d2q))/reference/ReferencesPapers.as px?ReferenceID $=855107$ https://doi.org/10.1016/j.foreco.2006.05.055

[24] Hoffmann, J. (1998) Assessing the Effects of Environmental Changes in a Landscape by Means of Ecological Characteristics of Plant Species. Landscape and Urban Planning, 41, 239-248. https://doi.org/10.1016/S0169-2046(98)00062-0

[25] Hojjati, S.M. (1999) Review of Natural Breeding Distribution of and Age Structure of Beech Forests in Fagetum Grazbon Section Khyrud Forest. Master of Science's Thesis, Department of Natural Resources, Tehran University, Tehran, 67.

[26] Marvie-Mohadjer, M.R. (1976) Some Qualitative Characteristics of Iranian Beech Forests. Iranian Journal of Natural Resources, 34, 77-96.

[27] Marvie-Mohadjer, M.R. (2011) Silviculture. University of Tehran Press, Tehran.

[28] Mataji, A., Kafaki, S.B., Safaee, H. and Kiadaliri, H. (2008) Spatial Pattern of Regeneration Gaps in Managed and Unmanaged Stands in Natural Beech (Fagus Orientalis) Forests. Iranian Journal of Forest and Poplar Research, 16, 149-157. http://en.journals.sid.ir/ViewPaper.aspx?ID=112700

[29] Majumdar, K., Choudhary, B.K. and Datta, B.K. (2016) Aboveground Woody Biomass, Carbon Stocks Potential in Selected Tropical Forest Patches of Tripura, Northeast India. Open Journal of Ecology, 6, 598-612. http://www.scirp.org/journal/PaperInformation.aspx?PaperID=70814 https://doi.org/10.4236/oje.2016.610057

[30] Moeur, M. (1993) Characterizing Spatial Patterns. Forest Science, 39, 756-775. http://www.ingentaconnect.com/content/saf/fs/1993/00000039/00000004/art00012

[31] Shahnavazi, H., Sagheb Talebi, K. and Zahedi Amiri, A.H. (2005) Evaluation Qualitative and Quantitative of Regeneration in Created Gap of Fagetum Golband (Section Jemand). Journal of Forest and Poplar Research, 83, 155-141.

[32] Mirzaei, J., Akbar Nia, M., Hosseini, S.A.M., Tabari, M. and Jalali, S. (2007) Compared to Non-Woody Species Density of Natural Regeneration in Relation to Physiographic and Soil Factors in Zagors Forests, of Trees Using Stem-Mapped Data. Forest Science, 39, 756-775. 
[33] Kenderes, K., Miho, K.B. and Standovár, T. (2008) Thirty Years of Gap Dynamics in a Central European Beech Forest Reserve. Forestry, 81, 111-123. https://doi.org/10.1093/forestry/cpn001

[34] Emborg, J., Christensen, M. and Helmann-Clausen, J. (1990) The Structural Dynamics of Sesurup Skov, Anear Natural Temperate Decidous Forest in Denmark. Forest Ecology and Management, 126, 173. https://www.cabdirect.org/cabdirect/abstract/19970608873 https://doi.org/10.1016/S0378-1127(99)00094-8

[35] Mousavi, Z.R., Sagheb-Talebi, K., Tabari, M. and Pour Majydyan, M.R. (2003) Determine the Size of Gaps Level for Improved Breeding Beech Canopy. Iranian Journal of Natural Resources, 56, 39-46.

[36] Gagnon, J.L., Jokela, E.J., Moser, W.K. and Huber, D.A. (2004) Characteristic of Gaps and Natural Regeneration in Mature Longleaf Pine Flatwood Ecosystems. Forest Ecology and Management, 187, 373. https://doi.org/10.1016/j.foreco.2003.07.002

[37] Zahedi Amiri, G.H. and Mohammadi Lymaye, S. (2002) The Relationship between Ecological Groups of Plant Grass on the Stage of with Habitat (Case Study: Forest Myanband neka). Iranian Journal of Natural Resources, 55, 353-341.

\section{Submit or recommend next manuscript to SCIRP and we will provide best} service for you:

Accepting pre-submission inquiries through Email, Facebook, LinkedIn, Twitter, etc. A wide selection of journals (inclusive of 9 subjects, more than 200 journals)

Providing 24-hour high-quality service

User-friendly online submission system

Fair and swift peer-review system

Efficient typesetting and proofreading procedure

Display of the result of downloads and visits, as well as the number of cited articles

Maximum dissemination of your research work

Submit your manuscript at: http://papersubmission.scirp.org/

Or contact oje@scirp.org 